\title{
Quality of Qualitative Research: A Grounded Theory (GT) Approach with Special Reference to Straussian GT
}

\author{
Udaya Mohan Devadas \\ Department of Human Resource Management, Faculty of Commerce and \\ Management Studies, University of Kelaniya, Sri Lanka \\ mohanudaya395@gmail.com \\ iD https://orcid.org/0000-0002-4617-1409
}

\begin{abstract}
This review was dedicated to discuss the core measures established evaluating the quality of Grounded Theory (GT) that have been highlighted by the main authors of GT with special reference to Straussian GT. Sraussian GT includes the work of Strauss and Corbin (1990 \&1998); Corbin and Strauss (2008); and Charmaz (2006). Glaser alone develops the Glasarian GT approach. First, I explained the concept of evaluation of a research in relation to its quality discussing some rigorous methods of establishing quality in qualitative research. Second and finally, the specific canons and procedures established specially in the Straussian GT methodology in establishing quality were discussed. Here, the related content in the ground breaking research of Glaser and Strauss in 1967 has been first referred following the Glaser's (1998) views in this regard before discussing the Straussian perspective on quality in GT research.
\end{abstract}

Keywords: Quality, Qualitative Research, Grounded Theory, Straussian Grounded Theory

\section{Introduction}

The acceptance of a research output purely depends on the quality maintained in the research process applying the standard protocol as suggested in particular research approach, research paradigm, research strategy and research method. A demarcation of a researcher's work from the work of general media worker or social worker or laymen's investigation or criminal investigator or an artist is based on the expected quality maintained with accepted rigor in the research process. However, in assessing the quality of qualitative research has been a challenge unlike in quantitative research. This is mainly due to the agility and flexibility given 
in qualitative research process, creativity that qualitative researcher use in research design and acceptance of bias and subjectivity in qualitative research paradigm. Thus, knowing about general rules of achieving quality in qualitative research and specific measures to be taken under alternative qualitative research methods is critically important. Therefore, the purpose of this paper is to construct a conceptual framework that guide to establish quality in qualitative research process, developed based on primary literature review.

\section{Methodology}

The current study uses a primary literature review as the method of the study. Literature was selected from the core articles and books written by the original authors who contributed to develop the Straussian grounded theory. The literature review targeted at accumulating general procedures of achieving qualitative research and grounded theory canons and procedures of preserving quality. Thus, similar literature were search for corroborating an accepted guiding model for the purpose.

\section{Organization of Review Findings}

Literature review was organized mainly to explain what quality is in qualitative research, to understand general guidelines given in preserving quality in qualitative research, and to investigate into grounded theory guidance in establishing quality in research while emphasizing Straussian grounded theory protocol for achieving quality in GT studies. Finally, the review findings were integrated into a guiding model of establishing quality in qualitative research for users to focus rightly in qualitative study process.

\section{Explaining Quality in Qualitative Research}

A qualitative research needs to generate a meaning irrespective of generalization based on statistical representation. In order to fulfill this need the biggest challenge that the qualitative researcher has faced is to establish the research's rigor that will enhance the reader's credibility. In this instance, an essential ingredient a qualitative research should possess is the 'expected quality'. 'Quality of the qualitative research must address the requirements of the method apply, meet the standards of the research 
community, and create value to the reader. According to Corbin \& Straus, (2008), quality of qualitative research must:

“...resonate with the reader's lie experiences that have substance, give insights, and shows sensitivity. It's a sufficient conceptualization with descriptions allowing reader to reach his or her own conclusions about the data and judging the credibility of the data analysis. It is creative in its conceptualizations but grounding in data" (p.305).

\section{General Measurements for Quality in Qualitative Research}

The literature highlights several ways of delivering quality in qualitative research. Referring to others work, Corbin and Strauss (2008) present validity and rigor (Mays \& Pope, 1995); trustfulness, or goodness (Emden \& Sandelowski, 1999); or integrity (Watson \& Girad, 2004) as ways of establishing quality in qualitative research. However, according to Flick, (2002) "how to assess qualitative research is not still resolved" (p. 218). Further, some scholars do not agree on some items in the list as the ways in establishing quality in qualitative research. Sparkes (2001) claimed that agreeing about validity by qualitative health researchers is a myth. Validity is a measurement in quantitative research. Unlike quantitative research according to Corbin and Strauss (2008), “... qualitative research is both scientific (Morse, 1999) as well as "creative" and "artistic" endeavor and the quality of the findings should reflect both of these aspects" (p. 298). Corbin and Strauss (2008), referring to Hammersley (1987), Winter (2000) pointed out that in qualitative research validity is the truth. However, some are of the view that qualitative researcher must take actions for validity and reliability during his action (Corbin and Strauss, 2008). Some criteria for ensuring validity (Whittemore et. al., 2001) are “... vividness; creativity; thoroughness; congruence or sensitivity” (p.531).

Corbin \& Strauss, (2008) further presented some necessities for constructing quality as mentioned in the table 01 . 
Table 01: Prerequisites for constructing quality in GT research

\begin{tabular}{|c|c|}
\hline 0 & $\begin{array}{l}\text { Methodological consistency (Flick, 2002)-method slurring loose } \\
\text { the credibility associated with the method }\end{array}$ \\
\hline o & Having a clarity of purpose-descriptive or generating theory \\
\hline o & $\begin{array}{l}\text { Having self-awareness (knowing about his biases and } \\
\text { assumptions)—writing the }\end{array}$ \\
\hline ० & $\begin{array}{l}\text { Researcher's reactions and feeling during the data collection and } \\
\text { analysis }\end{array}$ \\
\hline o & Having training on doing qualitative research \\
\hline ० & $\begin{array}{l}\text { Having a feeling and sensitivity for the topic, participants, and for } \\
\text { the research (for more credible not for valid) findings }\end{array}$ \\
\hline o & Must be willing to work hard for creativity- \\
\hline ○ & Moving a methodological awareness \\
\hline o & $\begin{array}{l}\text { Desire to do research for his own sake (every one need not to do } \\
\text { research) }\end{array}$ \\
\hline
\end{tabular}

Source: Corbin \& Strauss, (2008)

Rigor in qualitative research is hugely talked as a mean of establishing quality of the qualitative research. Corbin and Strauss (2008) referring to Morse et al, (2002) discussed some strategies for establishing rigor: “...Investigator's responsiveness; methodological coherence; theoretical sampling and sampling adequacy; taking an active analytical stance and saturation" (p. 09). Creswell (1998), and Creswell \& Miller, (2000) highlighted eight procedures laid by Lincoln and Guba (1985) in establishing credibility and trust worthiness. They are: prolonged engagement and persistent observation in the field; triangulation; using peer review or debriefing; negative case analysis; clarifying researcher bias; in member checks; rich thick description; and external audit (More towards validity not to creativity).

\section{Establishing quality in Grounded Theory}

Credibility-Corbin and Strauss (2008) clearly discussed about the quality in grounded theory research. From the break through discovery of grounded theory by Glaser and Strauss (1967) up to now the core authors in GT 
discusses how to establish quality in its methodology using different terminologies. Glaser and Strauss (1967) mainly focused on the credibility of GT research as a way of ensuring quality under two main questions: (1) how to get readers to understand the theoretical framework; and (2) how to describe the data of the social world studies so vividly.

\section{i. Getting readers to understand the theoretical framework (sufficient details and descriptions for reader's enlightenments)}

Under this, they suggested to give “....an extensive abstract presentation of the overall framework and its principle associated theoretical statements" (p.228), at the beginning or at the end of the publication and the segments throughout it. This presentation is not difficult according to Glaser and Strauss (1967), and this presentation can be even aided by the emergent concepts.

\section{ii. How to describe the data of the social world studies so vividly (evidence on how the data were gathered and analysis was made)}

This is a standard approach "...to give data as evidence for conclusions, thus indicating how the analyst obtained the theory from data" (p. 28). In this case, presenting only enough materials to facilitate comprehension is sufficient. Direct quote from interviews or conversation is also possible. Summarizing events or persons by constructing readable case studies is also acceptable in this case. Describing events and acts and can give at least a back ground descriptions of places and spaces. Even the researcher can offer personal experience to show how events impinged upon himself/herself Researcher can unroll a narrative. The way of heading chapters can also help to convey sights and sounds

Alternative to the above two points, another way of conveying credibility is to the use of codified procedure for analyzing data to allow reader to understand how the analyst arrived at theory from data. When there is no such procedurisation in qualitative analysis, it creates impressionistic theory (p.229). It is more important to include procedures on how and how long to search for negative cases or how to find alternative hypothesis from qualitative data. They further suggested to link analytical procedures with the (standard/accepted) procedures for using qualitative data. 
Glaser and Strauss (1967) discusses about how to judge credibility. According to them, if the reader is sufficiently been caught up in the description, so that he feels vicariously that he was also in the field, and then he is more likely to be disposed toward the researcher's theory. Further, they direct the reader for his/her judgment upon how the researcher came to his conclusions by noting: the range of events observed; interviewees; who talked to the analyst; what diverse groups the analyst compared; what kind of experience the analyst had; and how the analyst might have appeared to various people whom he/she studied. Examining the source of data used, what is explicitly stated in the study, and what the researcher red in between the lines will also become important in judging the credibility.

As another alternative, multiple comparison groups increase the credibility. In this instance detailing the similarities and dissimilarities of different groups under few social setting and different conditions, under which the researcher's hypothesis are minimized and maximized, and identifying what social setting is applicable to the theory will be beneficial for a successful comparison. Such comparisons further Increase the scope and help delimiting the generality of the theory. On the other hand multiple comparisons avoid reader's difficulty of assessing the applicability of the theory (that is called as 'discounting processes). This discounting process has several forms: theory is corrected; adjusted to fit diverse social structures; invalidated for other structures through the reader's experience or knowledge; and deemed inapplicable to yet other kinds of structures. This can enable the researcher to write his theory in general form since the reader has the qualifications to adjust, invalidate; and to correct. Researcher gives clear statements of theory and description and the reader can carefully asses the credibility of the theoretical framework he offers. If the research feels dubious about an important event, then he must specify explicitly upon what kind of data his interpretation rests. The reader should demand explicitness and if it is not there, then he must assess his interpretations from indirect evidence.

Applicability-Glaser and Strauss (1967) has talked about applicability as a way of improving the quality of research. Here the term they used is 'fit'. According to Glaser and Strauss (1967), "fit to the areas of its born and 
where it is to be used in; understandable; sufficiently general; provide the user with sufficient control to bring about change in situations" (p. 238). Corbin and Strauss (2008) has identified the term 'fit' as the most important rather using different terms for establishing quality. According to them, "If it fits and useful because it explains or describes things, then what is all the concern about rigor and everything? Rigor must have built into the research process" (p. 301). However, rigor in GT has been emphasized by some authors. Chiovitti and Piran (2003) present the some steps to establish rigor in GT research as given in table two below.

\section{Table 02: Establishing rigor in GT research}

- Let the participant guide the process

- Check the theoretical construction generated against participants' meanings of the phenomenon

- Use participant's actual words in the theory

- Articulate the researcher's personal view and insights about the phenomenon explored

- Specify the criteria built into the researcher's thinking

- Specify how and why the participants included in the study were selected

- Delineate the scope of the research

- Describe how literature relates to each category which emerged in the theory.

Source: Chiovitti and Piran (2003)

Trust -Glaser (1998) dealt with 'trust' in GT as a mean of establishing quality, under which he identified Fit, relevance, work, and modifiability as the four pillars of trust. Fit is about going right to the data and generating concepts from it, and constantly adjusting the best word to denote pattern emerged through the constant comparison. Relevance is related to the true issues of the participants in the substantive area. Work is the result of fit and relevance. If the theory works then it should be able to understood and applied. Modifiability is the ability of the theory to modify as the results of the further constant comparisons made by the later studies. Literature review also modify the theory when appropriate. 
Strauss and Corbin (1990) provide some specific criteria for judging a Grounded Theory research. It should be mentioned that, this has been the first initiative taken to discuss the rigor in GT research for establishing its quality that lie the foundation to other later work of GT author such as Corbin and Strauss (2008), and Charmaz (2006).

Adequacy-Strauss and Corbin (1990) discussed on how to Judge the adequacy of the research process by getting the answers for the questions given in table 3 .

\section{Table 03: Adequacy of the GT research process}

i. How the original sample was selected? What grounds?

ii. What major categories emerged?

iii. What were some of the events, incidents, actions, and so on that pointed to some of these major categories?

iv. On the basis of what categories did theoretical sampling proceed? That is, how did theoretical formulations guide some of the data collection? After the theoretical sampling was done, how representative did these categories prove to be?

v. What were some of the hypothesis pertaining to conceptual relationships? And on what grounds they formulated and tested?

vi. Were there instances when hypothesis did not hold up against what was actually seen?

vii. How and why was the core categories selected?

Source: Strauss and Corbin (1990)

Empirical Grounding- GT Further in order to empirical grounding of the study, they suggested the questions given in table 4 . 
Table 04: Empirical Grounding of GT studies

i. Are concepts generated?

ii. Are the concepts systematically generated?

iii. Are there many conceptual linkages and are the categories well developed? Do they have conceptual density?

iv. Is much variations built into the theory?

v. Are the broader conditions that affect the phenomenon under study built into its explanation?

vi. Has process been taken into account?

vii. Do the theoretical findings seem significant and to what extent?

viii. Do the findings become part of the discussions and ideas exchanged among relevant social and professional groups?

Source: Strauss and Corbin (1990)

Table 05: Starussian GT quality Criteria

- $\quad$ Fit- resonating with the intended audience and the participants of the study

- Applicability-use of the new insights developed

- Conceptualization-concepts should be developed in terms of their properties and dimensions for density and variations

- Contextualization of concepts by:

○ Logic-logical flow of ideas, meaningful findings, no missing links, making clear about the methodological decisions

- Depth- It is the descriptive details that add the richness and variation and lift the findings out of the realm of the ordinary. Depth of substance are not thin and uninterested findings, they should have a potential to make a change in policy and practice.

- Variation-different cases to capture the complexity of the life

- Creativity- Are the findings presented in a creative and innovative manner? Something new?

- Sensitivity- To the participants and the data. Has the analysis led the research or the preconception

- Memo-Providing the evidence of memos

Source: Corbin and Strauss (2008) 
Originality, resonance, and usefulness- Charmaz (2006) however used credibility, originality, resonance, and usefulness as the ways of establishing quality in her constructivists grounded theory methodologies. Straussian GT quality criteria- In judging the quality of qualitative research Corbin and Strauss (2008) used the methods mentioned in table 5.

\section{Conclusion}

This review explained quality criteria: generally used in qualitative research Grounded theory presented in 1967; Glaser's GT research presented in 1990; Straussian GT research presented by Corbin and Strauss in 1990, Charmaz's GT presented in 2006, and Corbin and Strauss's GT in 2008. Further the study highlighted the evaluation of quality in qualitative research is still not sorted out, and is differently viewed by different scholars. However, the main emphasis is on following an acceptable set of procedures in the research process so as to give an expected meaning to the reader, adopting an appropriate rigor in its methodology and meeting the requirements of the research community. Although there is no proper consensus on this matter, main authors in GT methodology shares some common characteristics in explaining the evaluation of quality of qualitative research. Thus, based on the review, I present the model depicted in Figure 1 to be followed as a common guide to be adopted in preserving quality in qualitative research. 
Figure 01: A model of preserving quality in Qualitative research

\begin{tabular}{|c|c|c|}
\hline $\begin{array}{c}\text { Readiness-Input } \\
\text { quality (quality for } \\
\text { preparing for research) } \\
\text { Methodological } \\
\text { consistency } \\
\text { Clarity of purpose } \\
\text { Self-awareness } \\
\text { Pre-training } \\
\text { Research sensitivity } \\
\text { Willingness } \\
\text { Methodological } \\
\text { awareness } \\
\text { Desire }\end{array}$ & $\begin{array}{l}\text { Action-Process quality } \\
\text { (quality during } \\
\text { research process) } \\
\text { Validity } \\
\text { Reliability } \\
\text { Credibility } \\
\text { Truthfulness } \\
\text { Goodness } \\
\text { Integrity } \\
\text { Trustworthiness }\end{array}$ & $\begin{array}{c}\text { Result-Output quality } \\
\text { (quality after } \\
\text { research/in outputs) } \\
\text { Trust } \\
\text { Originality } \\
\text { Resonance } \\
\text { Usefulness } \\
\text { Applicability } \\
\text { Modifiability } \\
\text { Fit } \\
\text { Relevance } \\
\text { Work } \\
\text { Integrity }\end{array}$ \\
\hline \multicolumn{3}{|c|}{$\begin{array}{l}\text { Control-Throughout Quality (quality controlling overall } \\
\text { research) } \\
\text { Adequacy, Rigor, Empirical grounding, Memo writing } \\
\text { Contextualization, Conceptualization }\end{array}$} \\
\hline
\end{tabular}

\section{References}

Charmaz, K. (2006). Constructing grounded theory, Thousend Oaks, CA: Sage

Corbin, J., \& Strauss, A. (2008). Basics of Qualitative Research 3e (3rd ed.). Los Angeles: Sage Publications.

Creswell, J. W. (1998). Qualitative inquiry and research design: Choosing among five traditions. Thousand Oaks, CA: Sage

Creswell, J. W., \& Miller, D.L. (2000) Determining validity in qualitative research. Theory into practice 39 (3), 124-130 
Flick, U. (2002). An Introduction to qualitative research ( $2^{\text {nd }}$ Ed.). Thousand Oaks, CA: Sage.

Glaser, B. G. ( 1992). Basics of Grounded THeory Analysis. Mill Valley: Sociology Press.

Glaser, B. G. (1978). Advances in the Methodology of Grounded theory: Theoritical Sensitivity. California: The Sociology Press.

Glaser, B. G. (1998). Doing Grounded Theory: Issues and Discussions. Mill Valley: Sociology Press.

Glaser, B. G., \& Strauss, A. L. (1967). The Discovery of Grounded Theory: strategies for qualitative research. New York: Aldine De Gruyter.

Sparkes, A.C. (2001). Myth 94: Qualitative health researchers will agree about validity. Qualitative Health Journal, 11(4), 538-552.

Strauss, A., \& Corbin, J. (1990). Basics of qualitative research: Grounded theory procedures and techniques, London: Sage

Whittemore, R., Chase, S., \& Mandle, C.L. (2001). Validity in qualitative research. Qualitative health research, 11(4), 522-537. 